\title{
An ecological approach for estimating turbidity in a river
}

\author{
F. Brancati, A. De Vincenzo, C. Martone \& R. Viparelli \\ Department of Environmental Physics and Engineering, \\ University of Basilicata, Italy
}

\begin{abstract}
In purging and disposal of sediments operations of a reservoir it is necessary to know the values of turbidity in the river downstream in natural conditions. This paper shows that under these conditions, in the absence of dams or river training works, the ratio of the average values of sediment discharge to the annual maximum value of water discharge is a function of the average annual turbidity. Turbidity can be regarded as representative synthetic index of the climatic conditions, the lithological features and the land cover of the basin, and the geometric characteristics of the river network. The proposed relationship of sediment discharge as a function of water discharge were validated on the basis of data from different regions of Italy, with very different morphological, geolithological and rainfall characteristics, and with basin area changing between a few dozen and thousands of square kilometres. The results can be considered satisfying.
\end{abstract}

Keywords: reservoir siltation, flushing, turbidity, environmental and morphological impact.

\section{Introduction}

As required by European legislation, flushing operations must not affect the survival of ecosystems. It is therefore necessary to define the flow values by which you can carry out the flushing so as to not alter the morphodynamic equilibrium of the hydrographic network downstream of a barrage, and simultaneously to not have impacts on the survival of river ecosystems.

In order to investigate the effects that a flushing operation may have on the downstream fluvial stream morphology and ecosystem, it is necessary both to 
analyze the values that sediment discharge $\mathrm{Q}_{\mathrm{s}}$ and water flow $\mathrm{Q}$ can have during the opening of bottom outlets and to compare them with those compatible with the morphological equilibrium of the downstream river and with the preservation of ecosystems.

\section{Qs and $Q$ values compatible with the morphological equilibrium of the river bed downstream a barrage}

The possibility of releasing in the riverbed waters from bottom outlet during flushing operations is closely linked with the transport capacity of the downstream river channels. This capacity, as we know, is in turn closely dependent on morphological characteristics and equilibrium conditions of downstream riverbed.

On the other hand, in equilibrium condition the morphological features of a fluvial stream depend on how the sediment discharge $\mathrm{Q}_{\mathrm{s}}$ under natural conditions, in the absence of barrages, are related to the ordinary flows, usually equal or related to the channel formative flow $\mathrm{Q}_{\mathrm{m}}$. For the formative flow river network change to achieve the dynamic equilibrium condition, where neither sedimentation nor erosion phenomena occur. In such a condition, the sediment discharge $\mathrm{Q}_{\mathrm{s}}$ transported by $\mathrm{Q}_{\mathrm{m}}$ is constant in moving from upstream to downstream of each fluvial stream.

In view of this, in the paper [1] 28 different river basins have been considered. These basins are located in various regions of Italy, with morphological, geolithological and pluviometric characteristics very different, with basin areas extremely variable (from dozens up to thousands of square kilometers) and number $\mathrm{N}$ of recording years long enough to be considered statistically significant.

In order to identify a law that defines how the sediment discharge $Q_{s}$ under natural conditions is related to the ordinary flows, a parameter that summarizes all the environmental parameters, or at least those most significant, has been chosen. This parameter is the average annual turbidity $\bar{T}\left(\frac{\mathrm{kg}}{\mathrm{m}^{3}}\right)$, average value of the $(365 \cdot N)$ values of turbidity daily recorded during the observation period. $\bar{T}$ influences both the production of solid material from basin slopes and the sediment transport along the river network. Turbidity, in fact, certainly depends on the following factors [2-9]:

- pluviometric features of the basin, because for the same geolithological characteristics and land use, with increasing annual average rainfall superficial erosion from slopes increases, and with increasing maximum value of daily rainfall sediment supply to the fluvial network due to landslides increases also;

- erodibility of soils and practices of land use, that affect the sediments supplied to hydrographic network; 
- conformation of the hydrographic network (slope, cross sections and mean velocity), which determines the network capacity to carry sediments coming from basin slopes.

It is difficult to assess how turbidity is affected by the above factors. Each of these, however, is in any case related to the basin area S. In the paper [1] the authors have investigated if the average turbidity was related to the basin surface upstream of each gauging station taken into account. The analyzed experimental data, even if referred to basins located in different regions of Italy, with very different geolithological and pluviometric features and basin areas extremely variable, are interpolated by the regression line:

$$
\bar{T}=0.003 \cdot S
$$

with a correlation coefficient $\mathrm{R}^{2}$ of 0.82 , certainly statistically significant.

This indicates that relationship (5) allows, when the basin area upstream a cross-section in a hydrographic network is known, to evaluate a synthetic parameter, physically powerful, which summarize the characteristics of the basin and its hydrographic network.

From the above, it follows that the operations of flushing can be made if sediment discharge and water flow released downstream of a dam are close to those characterizing the equilibrium state in natural conditions.

To this aim, assessing the transport capacity of the hydrographic network downstream of the dam will be necessary.

In this paper, for example, the case of gravel bed streams that have already reached equilibrium conditions is considered.

In such streams, a flushing could cause erosion or deposits if the concentration of the released mixture is respectively lower or higher than that corresponding to the equilibrium state. Of course, these phenomena can affect the equilibrium of the considered stream only if the released mixture flows in the downstream riverbed for a time at least equal to that occurs under natural conditions.

As demonstrated in eqn. (1), in gravel bed rivers in equilibrium state the mixture concentration $\mathrm{p}$, defined as a function of sediment and water specific weights $\gamma_{s}$ and $\gamma$

$$
p=\frac{\gamma_{S} \cdot Q_{S}}{\gamma \cdot Q}
$$

can be expressed by eqn. (3)

$$
M=0,061 \cdot p^{0,214} .
$$

that relates $\mathrm{p}$ to the dimensional transport index $\mathrm{M}$ defined by eqn. (4):

$$
M=\frac{Q^{\frac{1}{18}} \cdot i_{f^{\frac{1}{2}}}}{d_{f^{\frac{1}{6}}}^{\frac{1}{g^{\frac{5}{9}}}} .}
$$


Eqn. (4) links the transport index $M$ with the flow $Q$, the equilibrium bed slope if and the sediment mean diameter $\mathrm{d}_{\mathrm{f}}$ of the riverbed in study.

Of course, flushing operation is allowed only if both the values $\mathrm{p}$ and $\mathrm{Q}$ are compatible with the values of $M$ that resolves eqn. (3) and eqn.(4).

\section{$3 Q_{s}$ and $Q$ values compatible with the ecosystem preservation of the river bed downstream a barrage}

For the protection of river ecosystems, we can take cue from the calculation methods of minimum instream flow [10-14]. In this view, in order to define the flow concentration to be released downstream a barrage to ensure the preservation of the physical and chemical characteristics of the water body and the maintenance of living species typical of local natural conditions, the morphological characteristics (bed slope and channel width), the mean diameter of bed sediments and the fish species that populates the stream in study are taken into account.

To this end, some of the proposed methodologies for calculating the minimum instream flow suggest to use the "habitat suitability curves" of fish species that inhabit the river stream in study. As known, survival of aquatic organisms is also and essentially, from a purely hydraulic point of view, linked to the features of substrata and to the values of the flow hydrodynamic characteristics (flow and depth velocity). In particular, with regards to the substrata (table 1, referred to brown trout), bed sediment mean diameter is encrypted (with codes from 1 to 8 ) according to granulometry and nature of sediments (colloidal or not colloidal, organic nature, plant debris ..).

Table 1: Codification of the types of substrate for brown trout according to Bovee [11].

\begin{tabular}{|l|c|}
\hline Substratum & Code \\
\hline Plant and organic debris & 1 \\
\hline Clay - Silt & 2 \\
\hline Mud & 3 \\
\hline Sand & 4 \\
\hline Gravel & 5 \\
\hline Cobble & 6 \\
\hline Boulder & 7 \\
\hline Bed rock & 8 \\
\hline
\end{tabular}

Suitability curves (fig. 1, referred to brown trout) are then used to determine the suitability of a velocity, depth and substratum, for a given species and life stage.

These curves describe the behavioural characteristics of a life stage of a particular species with respect to each of the microhabitat variables. The peak of 
the curve gets a weighting value of 1 and represents the optimum value of a variable for use by a given life stage of a given fish species. The tails of the curve get a weighting of 0 . Where possible, the curves are empirically determined using instantaneous measurements of the distribution of fish over the range of the variable being examined at carrying water discharge.

It is obvious that the suitability curves are more restrictive for delicate fish species. In fig. 1 the suitability curves deducted for brown trout are shown: this species is often taken as a target species of the riverbeds as it requires survival conditions more restrictive than other salmonids and, above all, than cyprinids.
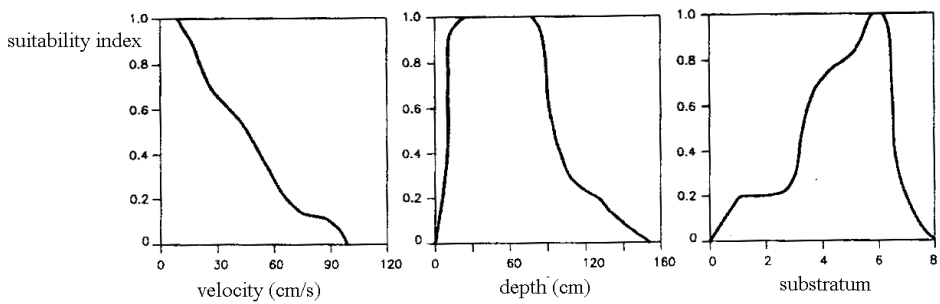

(a)
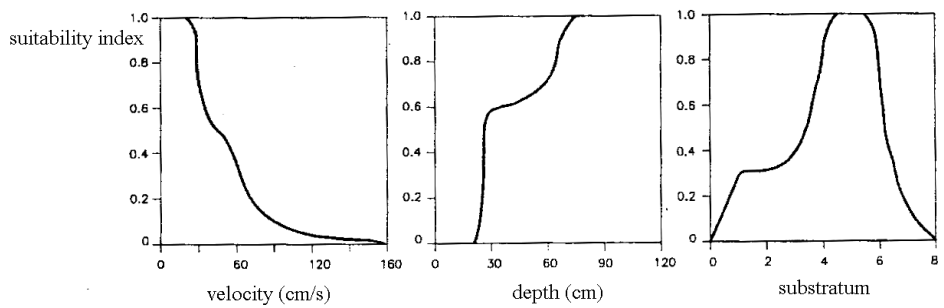

Figure 1: $\quad$ Preference curve for brown trout in juvenile (a) and adult (b) life stage.

As shown in fig. 1(b), a substratum of sand, with Code 4 (table 1), gives an excellent suitability index. This means that in fluvial streams populated by brown trout flushing operations that release sandy sediments are allowed. Such operations, however, should be avoided during periods of spawning of eggs in order to guarantee the fish conservation.

In this paper, it is proposed to determine the substratum suitability curve the range of diameter values of the particles to be released in a flushing operation in order to respect the river ecology conservation.

It follows that if the sediments to release have suitability indexes very low, the flushing operation is not allowed.

Otherwise, if the diameter of material to be released is known, we can admit that the preservation of ecosystems in terms of water turbidity is certainly ensured:

1 - if the concentrations values $\mathrm{p}$ of the flow released downstream during a flushing coincide with the average values of annual turbidity in natural conditions;

2 - if the flood wave caused by flushing is not too fast. 
The first requirement is satisfied when the concentration is equal to the value of $\bar{T}$ corresponding to the basin areas upstream of the river stream of interest (see law $\bar{T}(S)$ expressed by eqn. (1).

On the other hand, in order to maintain the morphological equilibrium, as stated in section n.2, it must be $p=\bar{T}$. Then, known $\mathrm{S}$ in the stream of interest, $p=\bar{T}$ is derived from eqn. (1). Under this $\mathrm{p}$ value, the transport index $\mathrm{M}$ expressed by eqn. (4) can be derived and so, known the values of bed slope and sediment diameter of the river channel downstream the barrage, the flushing flow $\mathrm{Q}$ can be calculated.

\section{Conclusions and remarks}

The paper proposes a methodology for calculating the concentration of the mixture to be released in the flushing operations compatible with the morphological equilibrium and the ecological protection of the river downstream the barrage.

The reservoir manager should plan the flushing operations taking into account the characteristics of the bottom outlet and the sediments to be released. The manager has to operate in a way as to ensure a flow of up to Q, taking also into account the water velocity close to the outlet, ensuring that the concentration $p=\bar{T}$ has not exceeded.

Of course, in a flushing operation the requirement $n .2$ is satisfied if the concentrations deduced by eqn.(3) are gradually achieved. Consequently, fixed the range of the operation values of the reservoir level $\mathrm{H}\left(\mathrm{H}_{\max } \div \mathrm{H}_{\min }\right)$, when the lake is at the $\mathrm{H}_{\max }$ level it is suggested to gradually open the bottom outlet, simulating the evolution of a natural flood wave. In this way is possible to prevent that flows and concentrations quickly increase, and thus to facilitate the fish movement to water more clear.

\section{References}

[1] De Vincenzo, A., Molino, B., Viparelli, R., \& Caramuscio, P., A methodological approach for estimating turbidity in a river, International Journal of Sediment Research, International research and Training Center on Erosion and Sedimentation (IRTCES), China, 2008.

[2] Davie, T., Fundamentals of hydrology, Routledge, London and New York, 2003.

[3] Linsley, R.K., Kohler, M.A. \& Paulhus, J.L.H., Hydrology for engineers, McGraw-Hill, New York, 1982.

[4] De Roo, A.P.J., Jetten, J.G., Wesseling, C.G. \& Ritsema, C.J., LISEM: A physically-based hydrological and soil erosion model incorporated in a GIS. Applications of Geographic Information Systems in Hydrology and 
Water Resources Management HydroGIS 1996, IAHS Publication No. 235, pp.395-403,1996

[5] Maione, U. \& Moisello, U., Appunti di idrologia - Le piene fluviali, La Goliardica Pavese, Pavia, pp. 50-52, 1977.

[6] Maione, U. \& Moisello, U., Elementi di statistica per l'idrologia, La Goliardica Pavese, Pavia, pp.74-77, 2003.

[7] Nash, J.E. \& Sutcliffe, J.V., River flow forecasting through conceptual models: Part I. A discussion of principles, Journal of Hydrology, 10, pp. 282-290, 1970.

[8] Viparelli, C. \& Viparelli, R., Bilancio idrologico di piena - connessione fra la distribuzione di probabilità delle portate al colmo di piena e le caratteristiche del bacino e della rete idrografica, Cuen, Napoli, 1989.

[9] Walling, D.E., The sediment delivery problem, Journal of Hydrology, 65, pp. 209-237, 1983.

[10] Binns, N.A., Habitat Quality Index Procedure Manual, Wyoming Game and Fish Department, 1982.

[11] Bovee, K.D., Probability of use criteria for the family salmonidae, Instream Flow Information paper n.4, Cooperative Instream Flow Group U.S. Fish and Wildlife Service, (78) 80, 1978.

[12] Bovee, K. D., A user's guide to instream flow incremental methodology, U.S. Fish and Wildlife Service, 1981.

[13] Stalnaker, C.B., Bovee, K.D. \& Waddle, T.J., Importance of the temporal aspects of habitat hydraulics to fish population studies, Regulated Rivers : Research and Management., 12, 1996.

[14] Tyus, H.M. \& Karp, C.A., Habitat and streamflow needs of rare and endangered fishes, Yampa River, Colorado, U.S. Fish Wildlife Service Biological Report, 89(14), 1989. 